\title{
Pairing effects and time-order errors in duration discrimination
}

\author{
DONALD G. JAMIESON and WILLIAM M. PETRUSIC \\ Carleton University, Ottawa, Ontario, Canada K1S 5B6
}

\begin{abstract}
The effects, measured in terms of reproductions, of pairing 4-sec-duration stimuli were examined for six ISIs varying between 1 and $26 \mathrm{sec}$. The results obtained in two experiments suggest that both members of a pair are affected by pairing, with the first-presented underestimated and the second-presented overestimated relative to unpaired durations. As well, unpaired durations tend to underestimate the standard. Each of these effects decreases in magnitude as ISI (delay) is increased. These results correctly predict the negative time-order errors observed in the comparison of durations, and were interpreted as suggesting a memory/perceptual phenomenon rather than a decision bias as a locus for the time-order errors observed in the duration comparison situation.
\end{abstract}

When subjects compare two successively presented stimuli, selecting the greater or the lesser of the pair, the pattern of responding observed often depends upon the order in which the stimuli are presented. Such presentation-order effects were discovered by Fechner, who reported that the second of a pair of weights tended to be overestimated relative to the first, producing what Fechner named a negative time-order error. ${ }^{1}$ Following Fechner, time-order errors were found to occur in many tasks, including brightness, loudness, taste, duration, line length, and visual extent comparisons (Needham, 1934; Woodworth, 1938). Most recently, Budohoska (1970) has demonstrated very sizable negative time-order errors in comparisons of brightness, of loudness, and of heaviness, although she does not discuss her results in these terms. In comparisons of duration stimuli, the early reports of negative time-order errors with durations of several seconds (see Woodrow, 1935, 1951. for discussion of this early work) have recently been confirmed in experiments by Jamieson and Petrusic (1975a, b), who also reported that time-order error magnitude decreases as the interstimulus interval (ISI) is increased. This dependence of time-order error magnitude upon the ISI immediately suggests that time-order errors in duration comparison may be related to the pairing of durations. In fact, there is evidence that pairing does affect judgments in other modalities. Peak (1939. $1940 \mathrm{a}, \mathrm{b})$, for example, showed that the pairing of tones affects judgments of the loudness, both of the

This research was supported by a National Research Council of Canada Postgraduate Scholarship to Jamieson, by grants from NRC and Carleton University to Petrusic, and by a grant from NRC to R. F. Dillon. We are further indebted to Dr. Dillon for his encouragement and for general advice. Reprint requests should be mailed to Don Jamieson. Department of Psychology. Carleton University, Ottawa, Ontario, Canada, K1S 5B6. first- and of the second-presented of the pair, relative to unpaired tones. Similar pairing effects on the memory/perception of the loudness of auditory stimuli are currently under investigation (e.g., Zwislocki, Ketkar, Cannon, \& Nodar, 1974; Zwislocki \& Sokolich, 1974). But duration may be the perfect modality for the examination of pairing effects, since subjects' reproductions of remembered durations may permit a direct measurement of the magnitude of those effects.

The present experiments had two purposes. First, they sought to determine the ways in which pairing durations affects the perception of the duration (measured in terms of reproductions) of the members of the pair. Second, they sought to determine whether these differences in reproductions could account for the consistently negative time-order errors observed when durations of several seconds are compared. The second experiment investigated pairing effects in individual subjects and used six ISIs varying between 1 and $26 \mathrm{sec}$. The first experiment investigated pairing effects in a larger sample of subjects but used a narrower range of ISI.

\section{EXPERIMENT I}

\section{Method}

Subjects. Sixteen introductory psychology students volunteered to serve for four $1 / 2$-h sessions in return for course credit. None had previously participated in a duration experiment and none was aware of time-order errors.

Apparatus and Stimuli. A DataGen Nova 1220 computer controlled timing, sequencing, and stimulus presentation, and recorded responses. The word "ready" was written on an Electrohome video monitor at the start of each trial. Stimulus durations were defined by the period of illumination of small light sources-red Monsanto light-emitting diodes (MV 5020). Two diodes, each $.47 \mathrm{~cm}$ in diam and having a rise/fall time of 50 nsec. were mounted on a clear plastic panel placed in front of the video monitor, with one diode $4 \mathrm{~cm}$ directly below the other. One stimulus duration-4 sec-and three ISIs-1, 6, and 11 sec-were 
used throughout the experiment. The subjects responded by pressing a response button on a panel interfaced with the computer.

Design. The experiment may be viewed as formed from the combination of three conditions: reproduction of a duration after a varying delay, denoted $\mathbf{R}_{u, d}$; reproduction of a duration separated from a preceding duration by a varying delay, denoted $R_{2}$; and reproduction of a duration followed, after a varying delay, by another duration, denoted $R_{1, d}$. These three conditions are displayed in Figure 1. The combination of the three delays-1, 6, and $11 \mathrm{sec}$-with these three conditions generated nine types of trial. During each session. two separate blocks, each containing each of the nine trial types in a completely random order, were presented. The subjects served for two sessions on the first day and returned at the same time 7 days later for a further two sessions.

Procedure. The subjects were run individually in a moderately illuminated room. The subject was seated at a desk which supported the visual display and the response panel, approximately $45 \mathrm{~cm}$ from the display. Each trial consisted of the following sequence: a word ("ready") was presented on the video screen and remained there until the subject pressed the response button to
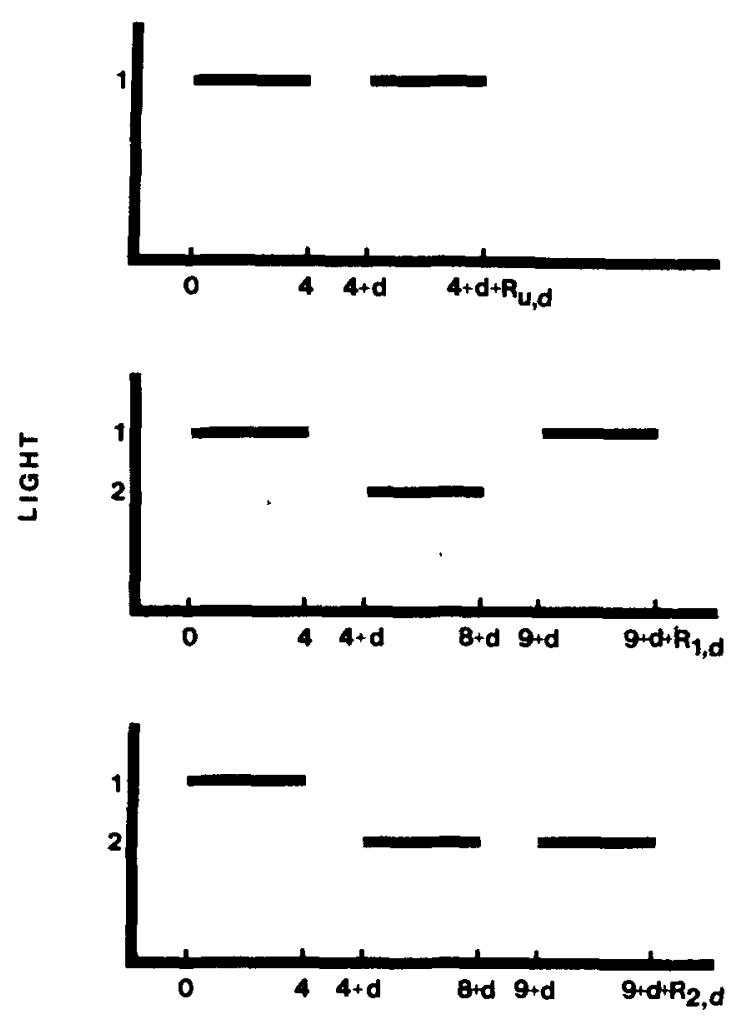

TIME IN SECONDS

Figure 1. The three experimental conditions: reproduction of a duration after a d-sec delay (top panel, reproduction denoted

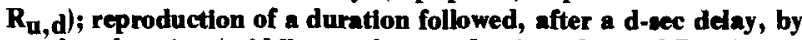
another duration (middle panel, reproductions denoted $\mathbf{R}_{1, d}$ ); and reproduction of $a$ duration, separated from a preceding duration by a d-sec delay (bottom panel, reproduction denoted $\mathbf{R}_{2}$,d). In each case, the first-presented durntion was represented by the period of illumination of the upper Iight (marked "1" here), while the second-presented duration was represented by the period of illumination of the lower light (marked " 2 " here). All duration stimuli were exactly 4,000 msec in duration; the delays, d, assumed the values 1, 6, and 11 sec in Experiment I, and 1, 6, 11, 16, 21, and 26 sec in Experiment $I$. initiate the trial; a delay of $1 \mathrm{sec}$ separated the removal of the word "ready" and illumination of the upper light for a duration of exactly $4 \mathrm{sec}$; after one of the nine possible combinations of ISI and stimulus presentation, a diode was illuminated to represent the to-be-reproduced duration; the subject pressed the response button to turn off the light when he judged that the appropriate interval had elapsed; a delay of $30 \mathrm{sec}$ was introduced prior to the presentation of the word "ready" for the next trial.

Three types of trials were described to the subject in terms of both the order and the position of the lights. The subject was told that each trial would begin with the illumination of the upper light and that he was to observe and remember the duration for which the light was illuminated. The subject was told that, after a delay, the upper light might be illuminated, in which case he was to press the button precisely when the present duration had exactly matched the earlier duration of the light. The subject was told that on other trials the lower light would be illuminated after the delay. He was. in this case, to observe the duration for which the lower light was illuminated and remember both the first-presented (upper) and the second-presented (lower) durations. He was then to reproduce the first or the second duration. depending on which light was presented; the first duration was to be reproduced if the upper light was illuminated and the second duration if the lower light was illuminated. In each case, he was to press the response button at that point in time at which the same light (upper or lower) had been removed earlier in the present trial. The subjects were requested to be as accurate as possible in their reproductions, but were told not to count or tap to mark the durations. They were told that the next trial would not start until they were ready and were encouraged to stretch or move about during the intertrial interval to help them to be alert during the next trial. The subjects were given no information about the range of durations that would be presented.

\section{Results and Discussion}

If pairing effects are responsible for negative time-order errors, pairing must increase the perceived duration of the second-presented stimulus (S2) and/or decrease the remembered duration of the first stimulus of the pair (S1). The hypotheses that these effects did, in fact, occur were tested by comparing, for each subject, the mean reproduction of each paired duration against the mean reproduction of the unpaired duration with the same presentationreproduction delay. Hence, the unpaired duration with the 1-sec delay $\left(R_{u, 1}\right)$ serves as the control for each $R_{2, d}$. since, in each case, the reproduction of $S 2$ followed presentation by exactly 1 sec. Similarly, since S2 was always $4 \mathrm{sec}$ and since reproduction began exactly $1 \mathrm{sec}$ after termination of S2 presentation, the appropriate control for the reproduction of $S 1\left(R_{1, d}\right)$ is the unpaired duration reproduced at a delay 5 sec greater than the ISI (i.e., $R_{u, d}+5$ ). Each of these comparisons was made for each subject separately. In general, and as expected (see Woodrow, 1933), there was considerable variability in the reproductions both between and within subjects, with means ranging between 2.64 and $4.31 \mathrm{sec}$ for the unpaired duration reproduced after $1 \mathrm{sec}$ and standard deviations varying between .29 and $1.73 \mathrm{sec}$ for reproductions of the unpaired duration after $11 \mathrm{sec}$, for example. Hence, to permit between-subject comparisons of the magnitude of the pairing effects, the comparisons were standardized for 
each subject by subtracting the appropriate control from the mean $R_{2, d}$, and then dividing this difference score by the control, i.e., $\left(R_{2, d}-R_{u, 1}\right) / R_{u, 1}$ for $d=$ $1,6,11$. Similarly, the appropriate control was subtracted from the mean $R_{1, d}$, and this value was divided by the control, i.e., $\left(\mathbf{R}_{1, d}-\mathbf{R}_{\mathbf{u}, \mathrm{d}+5}\right) /$ $R_{u, d+5}$ for $d=1,6$. Figure 2 , which presents the means of these standardized values collapsed across subjects, indicates that for the 1-sec ISI, the second of a pair of durations tended to be overestimated by approximately $14 \%$ relative to the control, while the first of the pair tended to be underestimated by about $7 \%[\mathrm{t}(15)=3.258), \mathrm{p}=.003$, and $\mathrm{t}(15)=-1.978, \mathrm{p}$ $=.037$, respectively, by one-tailed tests]. With the 6-sec ISI, these effects are in the same direction but are very small. One-way analyses of variance performed on the arcsine transformations of the standardized scores revealed a significant effect of ISI for $S 2[F(2,15)=9.32, p=.001]$; the effect of ISI was not signiticant for $\mathrm{S} 1[\mathrm{~F}(1,15)=1.49, \mathrm{p}=.241]$. Examination, only of the signs of the standardized scores, shows much the same trend: for $S 2,12,7$, and 5 of the 16 scores were positive at the 1-, 6-, and $11-\mathrm{sec}$ ISI, respectively, while 9 and 10 of the 16 S1 scores were positive at the 1- and 6-sec ISI, respectively.

These data suggest that pairing effects are large and in the direction required to produce negative time-order errors. To the extent that the reproductions represent the remembered/perceived durations, we can say that the second of a pair of durations appears longer and the first of the pair is remembered as being shorter than either would be, unpaired. Not all subjects, however, show these effects-indeed, not all subjects show the time-order error-but, at least for the S2, there may be good reason to exclude those that do not. Four subjects showed suspiciously low standard deviations-half those of any others-in their reproductions, suggesting that these subjects may have been counting or using some other technique in violation of instructions to aid performance. Of the 12 subjects remaining after these 4 subjects are eliminated, the predicted effects are shown by 11,5 , and 4 subjects for S2 and by 9 and 8 subjects for the S1 as ISI increases.

Predictions about the time-order errors which these data would generate if translated to the comparison situation depend upon the particular strategy the subjects are assumed to use in the comparison situation. If the subjects reproduce the first-presented duration during the presentation of the second, and select as the lesser that stimulus (reproduction) which is the first to terminate (Jamieson \& Petrusic, 1975a; Kristofferson, personal communication), the comparison of the reproduction of unpaired durations against the 4-sec standard is critical. If the subjects wait until both stimuli have been presented and then

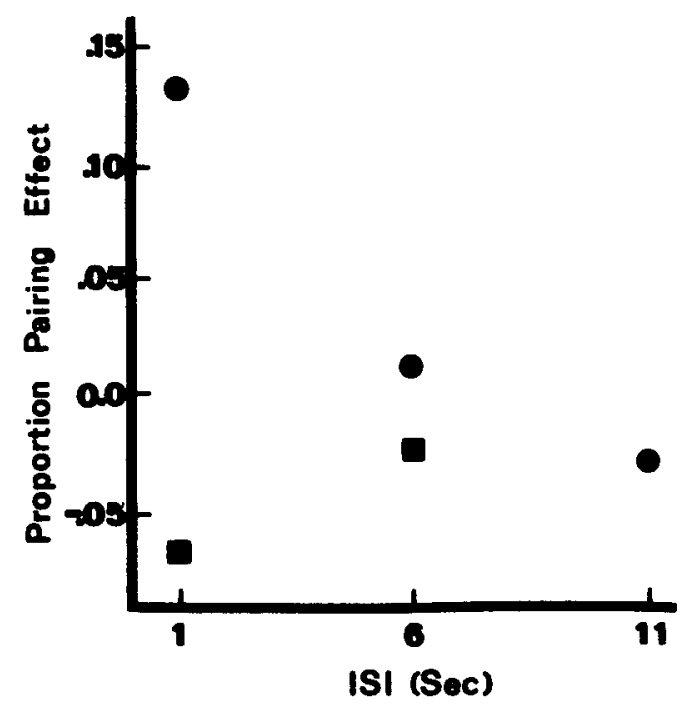

Figure 2. Means of standardized scores collapsed over 16 subjects in Experiment I. Parameter is reproduced stimulus of the pair: circles are scores for S2 reproductions at each ISI, while squares are scores for $S 1$ reproductions. Positive values indicate proportion overestimation relative to appropriate control, while negative values represent proportion underestimation.

compare the remembered durations, the appropriate comparisons are those of $R_{2, d}$ against $R_{1, d}$. As Table 1, which presents the means of the subjects' mean reproductions for each of the nine conditions, shows, either strategy should produce the negative time-order errors observed with short ISIs in the comparison situation. For 11 of 16 subjects and as shown in Table 1, reproductions of unpaired durations are very significantly less than $4 \mathrm{sec}$ at the $1-\mathrm{sec}$ ISI, a result in agreement with previous reports of underestimation of the standard stimulus by (mean) reproductions (e.g., Frankenhaeuser, 1959; Treisman, 1963; Vroon, 1972; Woodrow, 1933). Similarly, both in Table 1 and for 11 subjects, $R_{2, d}$ exceeds $R_{1, d}$ at the $1-s e c$ ISI. However, the time course of the time-order errors produced by neither strategy would match those observed in comparison experiments: using the reproduction strategy, the unpaired durations would predict a decrease in time-order error magnitude to nearly zero by the 6 -sec

Table 1

Experiment I: Reproductions of S1, S2, and Unpaired Duration Stimuli at the 1-, 6-, and $11-\sec$ ISIs (Respectively Delays)

\begin{tabular}{lccc}
\hline & \multicolumn{3}{c}{ ISI (Sec) } \\
\cline { 2 - 4 } Condition & 1 & 6 & 11 \\
\hline S1 & 3.74 & 3.82 & 3.89 \\
S2 & 3.97 & 3.62 & 3.48 \\
Unpaired & 3.57 & 4.02 & 3.92 \\
\hline
\end{tabular}

Note-Entries are means of 16 subjects' mean reproductions (in seconds) of 4-sec stimulus. 
ISI, while the comparison of $R_{2, d}$ with $R_{1, d}$ predicts time-order errors would become positive by the 6-sec ISI. The comparison data (Jamieson \& Petrusic, $1975 \mathrm{a}, \mathrm{b}$ ), on the other hand, show that time-order errors remain negative while decreasing in magnitude, at least to the 8-sec ISI.

These results provide considerable encouragement for the position that time-order errors in the comparison of pairs of durations may be related to the actual pairing of the durations. To further investigate these hypotheses, Experiment II was performed, using a larger number of ISI values and investigating pairing effects in individual subjects.

\section{EXPERIMENT II}

\section{Method}

Subjects. Four adult students volunteered to serve without pay for 1350 -min sessions. Two subjects had served in a previous duration experiment, but only one (D) was aware of time-order errors. Subject $S$ withdrew after seven sessions.

Procedure. The second experiment differed from the first in that six ISI values-1, 6, 11, 16, 21, and 26 sec-were used instead of three. The combination of the six delays with the three reproduction conditions yielded 18 types of trial. During each session, two separate blocks, each containing each of the 18 trial types in a completely random order, were presented. Other aspects of the experiment were precisely as described for Experiment $I$.

\section{Results and Discussion}

Sizable pairing effects, in the direction required for the production of negative time-order errors, were observed in Experiment II: the second of a pair of durations was overestimated, while the first of the pair was underestimated, relative to unpaired durations. The median, mean, and standard deviation of the reproductions for each of the $\mathbf{1 8}$ types of trial were computed separately for each subject. These statistics are presented in Table 2. Comparison of each value with the appropriate control shows the tendency to reproduce $\mathrm{S} 1$ as shorter and $\mathrm{S} 2$ as longer than comparable unpaired stimuli. For example, for Subject $\mathrm{R}$, mean $\mathrm{S} 1$ reproduction at the 1 -sec ISI was 2.98 , while the mean control reproduction, the unpaired duration reproduced after a delay of $6 \mathrm{sec}$ was 3.42. Similarly, the mean reproduction of $S 2$ at the 1 -sec ISI was $3.42,400 \mathrm{msec}$ greater than the control reproduction-the unpaired duration reproduced after a 1-sec delay. For reproductions of the second of a pair of durations, comparisons of mean values show the effect for all subjects; comparisons of median values show the effect in three subjects. Similarly, using either means or medians for comparisons, reproductions of S1 are shorter than the control for three of the four subjects. Standardized

Table 2

Experiment II: Median, Mean, and Standard Deviation of the Reproductions of S1, S2, and Unpaired Duration Stimuli at Each of the Six ISIs

\begin{tabular}{|c|c|c|c|c|c|c|c|c|c|c|}
\hline \multirow[b]{3}{*}{ Subject } & \multirow[b]{3}{*}{ Stimulus } & \multicolumn{9}{|c|}{ ISI (Delay) } \\
\hline & & \multicolumn{3}{|c|}{1} & \multicolumn{3}{|c|}{6} & \multicolumn{3}{|c|}{11} \\
\hline & & $X_{50}$ & $\overline{\mathrm{X}}$ & SD & $X_{50}$ & $\overline{\mathrm{X}}$ & SD & $X_{30}$ & $\overline{\mathrm{X}}$ & $\mathrm{SD}$ \\
\hline $\mathbf{R}$ & $\begin{array}{l}\text { Unpaired } \\
\text { S1 } \\
\text { S2 }\end{array}$ & $\begin{array}{l}2.80 \\
2.94 \\
3.10\end{array}$ & $\begin{array}{l}3.02 \\
2.98 \\
3.42\end{array}$ & $\begin{array}{l}.73 \\
.88 \\
.81\end{array}$ & $\begin{array}{l}3.41 \\
3.45 \\
3.45\end{array}$ & $\begin{array}{l}3.42 \\
3.32 \\
3.64\end{array}$ & $\begin{array}{l}.67 \\
.68 \\
.61\end{array}$ & $\begin{array}{l}3.56 \\
3.33 \\
3.59\end{array}$ & $\begin{array}{l}3.40 \\
3.68 \\
3.58\end{array}$ & $\begin{array}{l}.84 \\
.86 \\
.63\end{array}$ \\
\hline$S$ & $\begin{array}{l}\text { Unpaired } \\
\text { S1 } \\
\text { S2 }\end{array}$ & $\begin{array}{l}3.21 \\
2.66 \\
2.82\end{array}$ & $\begin{array}{l}2.95 \\
2.85 \\
3.13\end{array}$ & $\begin{array}{r}.93 \\
.82 \\
1.61\end{array}$ & $\begin{array}{l}3.44 \\
2.95 \\
4.12\end{array}$ & $\begin{array}{l}4.11 \\
3.01 \\
4.62\end{array}$ & $\begin{array}{r}2.37 \\
.75 \\
1.54\end{array}$ & $\begin{array}{l}3.67 \\
2.98 \\
2.74\end{array}$ & $\begin{array}{l}4.05 \\
2.95 \\
3.06\end{array}$ & $\begin{array}{r}1.64 \\
.95 \\
.81\end{array}$ \\
\hline $\mathrm{C}$ & $\begin{array}{l}\text { Unpaired } \\
\text { S1 } \\
\text { S2 }\end{array}$ & $\begin{array}{l}3.86 \\
3.96 \\
4.32\end{array}$ & $\begin{array}{l}4.02 \\
4.06 \\
4.42\end{array}$ & $\begin{array}{l}.78 \\
.83 \\
.96\end{array}$ & $\begin{array}{l}3.92 \\
4.46 \\
3.95\end{array}$ & $\begin{array}{l}4.05 \\
4.33 \\
4.13\end{array}$ & $\begin{array}{l}.93 \\
.61 \\
.87\end{array}$ & $\begin{array}{l}4.00 \\
4.35 \\
4.54\end{array}$ & $\begin{array}{l}4.21 \\
4.42 \\
4.36\end{array}$ & $\begin{array}{r}1.29 \\
.73 \\
1.23\end{array}$ \\
\hline \multirow[t]{2}{*}{ D } & $\begin{array}{l}\text { Unpaired } \\
\text { S1 } \\
\text { S2 }\end{array}$ & $\begin{array}{l}3.63 \\
3.41 \\
4.64\end{array}$ & $\begin{array}{l}3.52 \\
3.38 \\
4.59\end{array}$ & $\begin{array}{l}.63 \\
.70 \\
.96\end{array}$ & $\begin{array}{l}3.68 \\
3.44 \\
4.18\end{array}$ & $\begin{array}{l}3.67 \\
3.53 \\
4.32\end{array}$ & $\begin{array}{l}.67 \\
.68 \\
.94\end{array}$ & $\begin{array}{l}3.59 \\
3.34 \\
4.22\end{array}$ & $\begin{array}{l}3.79 \\
3.53 \\
4.51\end{array}$ & $\begin{array}{r}1.07 \\
.83 \\
1.19\end{array}$ \\
\hline & & \multicolumn{3}{|c|}{16} & \multicolumn{3}{|c|}{21} & \multicolumn{3}{|c|}{26} \\
\hline $\mathbf{R}$ & $\begin{array}{l}\text { Unpaired } \\
\text { S1 } \\
\text { S2 }\end{array}$ & $\begin{array}{l}3.80 \\
3.33 \\
3.46\end{array}$ & $\begin{array}{l}3.62 \\
3.49 \\
3.51\end{array}$ & $\begin{array}{r}1.13 \\
.88 \\
.65\end{array}$ & $\begin{array}{l}3.43 \\
3.79 \\
3.55\end{array}$ & $\begin{array}{l}3.41 \\
3.80 \\
3.44\end{array}$ & $\begin{array}{l}.70 \\
.89 \\
.63\end{array}$ & $\begin{array}{l}3.31 \\
3.70 \\
3.52\end{array}$ & $\begin{array}{l}3.56 \\
3.62 \\
3.49\end{array}$ & $\begin{array}{l}.94 \\
.85 \\
.51\end{array}$ \\
\hline $\mathrm{S}$ & $\begin{array}{l}\text { Unpaired } \\
\text { S1 } \\
\text { S2 }\end{array}$ & $\begin{array}{l}4.16 \\
2.98 \\
3.07\end{array}$ & $\begin{array}{l}3.90 \\
2.98 \\
3.06\end{array}$ & $\begin{array}{l}1.16 \\
1.05 \\
1.0\end{array}$ & $\begin{array}{l}3.97 \\
2.81 \\
2.81\end{array}$ & $\begin{array}{l}4.69 \\
3.02 \\
3.12\end{array}$ & $\begin{array}{r}2.21 \\
.85 \\
1.81\end{array}$ & $\begin{array}{l}3.90 \\
3.00 \\
2.56\end{array}$ & $\begin{array}{l}3.84 \\
3.26 \\
3.18\end{array}$ & $\begin{array}{r}1.42 \\
.99 \\
1.47\end{array}$ \\
\hline $\mathrm{C}$ & $\begin{array}{l}\text { Unpaired } \\
\text { S1 } \\
\text { S2 }\end{array}$ & $\begin{array}{l}4.43 \\
4.61 \\
3.75\end{array}$ & $\begin{array}{l}4.52 \\
4.72 \\
4.01\end{array}$ & $\begin{array}{l}.86 \\
.88 \\
.86\end{array}$ & $\begin{array}{l}4.66 \\
4.88 \\
4.02\end{array}$ & $\begin{array}{l}4.61 \\
4.89 \\
4.09\end{array}$ & $\begin{array}{r}1.22 \\
1.04 \\
.84\end{array}$ & $\begin{array}{l}5.36 \\
4.89 \\
4.00\end{array}$ & $\begin{array}{l}5.14 \\
4.59 \\
4.11\end{array}$ & $\begin{array}{r}1.06 \\
.94 \\
.89\end{array}$ \\
\hline $\mathrm{D}$ & $\begin{array}{l}\text { Unpaired } \\
\text { S1 } \\
\text { S2 }\end{array}$ & $\begin{array}{l}3.61 \\
3.57 \\
4.04\end{array}$ & $\begin{array}{l}3.91 \\
3.66 \\
4.13\end{array}$ & $\begin{array}{l}.78 \\
.56 \\
.86\end{array}$ & $\begin{array}{l}4.02 \\
3.56 \\
4.20\end{array}$ & $\begin{array}{l}4.11 \\
3.66 \\
4.29\end{array}$ & $\begin{array}{l}.99 \\
.52 \\
.86\end{array}$ & $\begin{array}{l}4.38 \\
3.63 \\
3.78 \\
\end{array}$ & $\begin{array}{l}4.41 \\
3.61 \\
3.95 \\
\end{array}$ & $\begin{array}{l}.86 \\
.91 \\
.75\end{array}$ \\
\hline
\end{tabular}

Note-Entries are in seconds for individual subjects. 
scores based on mean reproductions were calculated for each subject as described for Experiment I. The mean of each of these values, collapsed across subjects, is presented in Figure 3. This plot shows clearly the increment in the $\mathrm{S} 2$ reproductions and the decrement in the $\mathrm{S} 1$ reproductions due to pairing. Importantly, however, the pairing effects are evident even with an ISI as large as $26 \mathrm{sec}$. This result stands in contrast to Experiment I and can only suggest that the memories and perceptions of the experimental stimuli are influenced by the entire range of durations (including ISI) which are used in the experiment. Complex interactions between stimuli and ISI were previously reported by Roelofs and Zeeman (1949) for comparisons of duration stimuli, but the generality of their results is uncertain since they were obtained with a single subject who had previously served in a large number of experiments. Effects of the width of the range of stimuli presented within each session have also been found to influence the magnitude and direction of time-order errors in comparison experiments (Jamieson \& Petrusic, 1975b).

As discussed for Experiment I, there are two critical comparisons for explanations of the time-order error in duration comparison experiments based on the present data. The first type-comparison of $R_{1, d}$ with $R_{2, d}$ at each ISI-suggests that time-order errors would be negative for all subjects and would decrease in magnitude as the ISI increased. Indeed, S2 tended to be overestimated at the 1-, 6-, and 11-sec ISIs relative to S1. As Table 2 shows, this effect was shown for four subjects with the 1 -sec ISI (overall means, 3.89 and 3.32), for three subjects at the 6 -sec ISI (overall means, 4.18 and 3.54 ), and for two subjects at the 11 -sec ISI (overall means, 3.88 and 3.64). An estimate of the magnitude of the differences in reproductions of S1 and S2 was obtained by plotting, for each subject at each ISI, the cumulative proportions of $S 1$ reproductions less than each percentile of the distribution of $\mathrm{S2}$ reproductions, and then computing the area under the curve. The resulting values, which can be taken as an estimate of the probability that an $R_{2} d$ would exceed an $R_{1, d}$ (and hence of the probability of a negative time-order error on a comparison trial) are presented in Table 3. For each subject, these proportions exceed .5 initially and gradually decline with ISI. For three subjects, proportions become less than .5 with long ISIs. These results suggest that time-order errors would be negative for all subjects with short ISIs, but would eventually become positive with sufficiently long ISIs. The actual proportions of negative error predicted are low relative to the values interpolated from the (grouped) comparison data for the equal durations (near $5 \mathrm{sec}$ ) shown in the Jamieson and Petrusic (1975a) Figure 1 (.75, .64, and .61 , respectively, for the $1-, 6-$, and $11-\mathrm{sec}$ ISI).

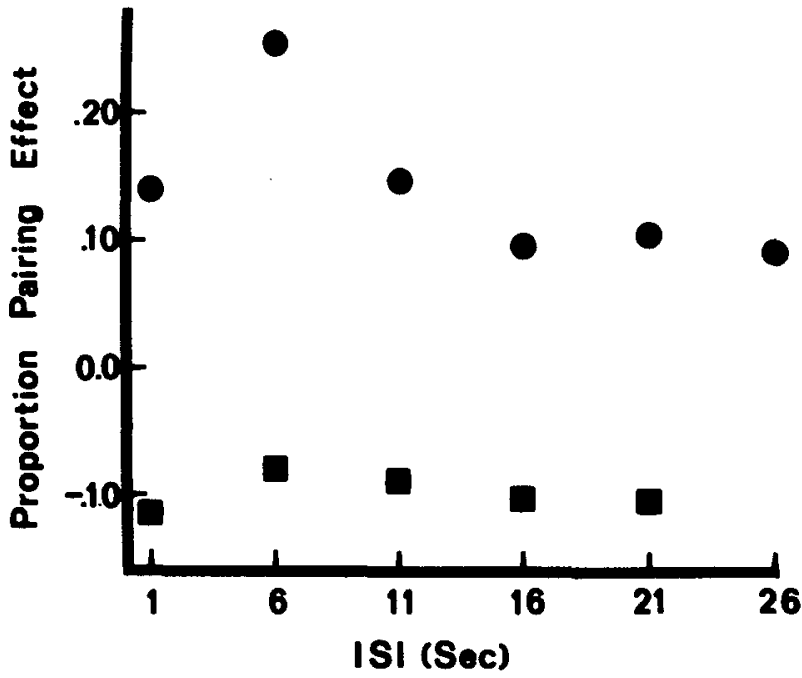

Figure 3. Means of standardized scores collapsed over four subjects in Experiment II. Circles represent scores based on mean reproductions of $S 2$, while squares are for mean reproductions of S1. Positive values indicate proportion overestimation relative to appropriate control, while negative values represent proportion underestimation.

The second comparison-that of reproductions of unpaired durations relative to the 4-sec stimulussuggests that time-order errors would be negative and large at the 1-, 6-, and 11-sec ISIs and would decrease in size with ISI. Table 4 presents, for each subject, the proportion of responses less than $4 \mathrm{sec}$ at each ISI. This table shows that a high proportion of unpaired reproductions were less than the 4-sec stimulus, with the proportion gradually decreasing as the delay was

Table 3

Experiment II: Estimates of the Probability of S1 Reproduction Not Exceeding S2 Reproduction at Each ISI

\begin{tabular}{lcccccc}
\hline Sub- & \multicolumn{7}{c}{ ISI } \\
\cline { 2 - 7 } ject & 1 & 6 & 11 & 16 & 21 & 26 \\
\hline R & .63 & .60 & .49 & .54 & .37 & .47 \\
D & .85 & .75 & .77 & .70 & .72 & .60 \\
S & .56 & .87 & .52 & .47 & .45 & .33 \\
C & .60 & .40 & .51 & .23 & .27 & .29 \\
All & .66 & .65 & .57 & .49 & .45 & .42 \\
\hline
\end{tabular}

Table 4

Experiment II: Proportion of Reproductions of Unpaired (4-Sec) Duration Stimuli Not Exceeding $4 \mathrm{Sec}$ at Each of Six Presentation-Reproduction Delays

\begin{tabular}{lcccccc}
\hline & \multicolumn{7}{c}{ ISI } \\
\cline { 2 - 7 } $\begin{array}{l}\text { Sub- } \\
\text { ject }\end{array}$ & 1 & 6 & 11 & 16 & 21 & 26 \\
\hline R & .88 & .88 & .83 & .56 & .79 & .67 \\
D & .88 & .79 & .67 & .63 & .46 & .25 \\
S & .93 & .50 & .57 & .43 & .50 & .50 \\
C & .54 & .50 & .46 & .21 & .28 & .28 \\
All & .81 & .67 & .64 & .46 & .51 & .42 \\
\hline
\end{tabular}


increased. The values in Table 4 overestimate the interpolated proportions of time-order errors in the comparison situation.

\section{GENERAL DISCUSSION}

While the differences between $R_{u, d}, R_{1, d}$, and $R_{2, d}$ are interpreted here as effects of pairing durations, other interpretations are possible. For example, the experimental tasks introduce different types of uncertainty which may influence the reproduction or coding of durations: prior to the reproduction of the unpaired duration and the presentation of $S 2$, the subject is unsure whether the coding or the reproduction of a duration will be required, while before the paired durations are reproduced, the subject is uncertain only as to which duration to reproduce. Evidently, some aspect of this task uncertainty could influence the coding of S2 or the reproduction of the unpaired duration. However, the precise way in which task uncertainty could interact to produce the present pattern of results is unclear, and such an explanation would predict no effects upon $S 1$ reproductions. As well, such a task-specific explanation would offer nothing to the problem of the time-order errors observed in the comparison situation.

If, as seems to us more reasonable, the present results are viewed as due to pairing stimuli, a number of conclusions can be drawn from the two experiments reported here. Pairing durations does affect the memory for and/or perception of the duration of stimuli, as measured by the reproductions of those stimuli. Both the first- and the second-presented of the pair are affected-the $S 1$ is underestimated and S2 overestimated relative to unpaired durations. Consequently, S2 reproductions tend to exceed S1 reproductions by an amount which decreases with ISI. Reproductions of unpaired durations tend to underestimate the to-be-reproduced duration, with the amount of underestimation decreasing with increasing presentation-reproduction delay. Finally, the time course of the pairing effects is uncertain, due perhaps to a complex interaction with interstimulus interval.

The demonstration of sizable effects of pairing stimuli, has clear implications for theory and research involving comparison paradigms. Clearly, approaches in which the independence of stimuli is a critical assumption [e.g., Green \& Swets (1966), Luce \& Galanter (1963), in the general case, and Creelman (1962), for duration] are challenged by these data. In fact, one reason that pairing effects and related local phenomena have not previously been investigated is precisely because they violate the assumptions of simple models. Duration comparison data may admit simple models to the extent that one is willing to ignore these local effects.

These data leave uncertain the actual locus of the time-order error in the comparison situation. Either the decrease in the reproduction of an unpaired stimulus relative to its presented duration, or the effects of pairing on the memory of $S 1$ and the perception/memory of S2 could account for these effects. The comparisons of amount of time-order error predicted and observed in the comparison case, made in Experiment II, supports neither explanation: the former overestimated the time-order error magnitude, while the latter underestimated it. In considering the validity of the numerical between-task comparison, however, it should be remembered that different subjects may use different strategies and that the comparison here was made with different stimuli as well as between separate groups of subjects. Only the simultaneous investigation of reproductions and comparisons with a single stimulus set and with individual subjects is likely to permit the two explanations to be distinguished. Among the notions which these data suggest can be eliminated are that criterion biases (e.g., Luce \& Galanter, 1963; Wickelgren, 1968) or response preferences are sufficient to explain the time-order errors observed when durations are compared (Allan \& Kristofferson, 1974).

The time-course of the time-order errors predicted by both explanations are curious in view of the research on time-order errors in other modalities. The result predicted here is a change from negative time-order errors with short ISIs to positive errors with longer ISIs. Such a result would be quite unique among time-order error phenomena, since the common result (Postman, 1946; Woodworth, 1938) is that positive errors occur at short ISIs and become increasingly negative as ISI increases. The demonstration of this occurrence in the comparison case would provide yet another instance (see Allan \& Kristofferson, 1974) in which durations behave very differently from other types of sensory stimuli.

Apparently, pairing effects in duration discrimination have been investigated but once previously. In that study (Huppert \& Singer, 1967), reproductions of 2 -sec auditory durations preceded by an adapting tone were compared to reproductions of 2 -sec durations which were unpaired. Huppert and Singer found that, at each of eight ISIs varying between .1 and $20 \mathrm{sec}$, the $\mathrm{S} 2$ was reproduced as shorter than were unpaired durations. The Huppert and Singer results, therefore. seem to contradict both the present results and the classical reports of negative time-order errors whenever durations longer than about $.7 \mathrm{sec}$ are compared (see Woodrow, 1935, 1951). However, since subjects had no reason to attend to the duration of S1 (they were never required to reproduce $\mathrm{S} 1$ ), it is not 
clear that their effect is due to pairing durations. Moreover, it is not clear whether negative time-order errors would have been generated by the S1-reproduction strategy since Huppert and Singer give no information about the actual distribution of reproductions, presenting only the differences between reproductions of $\mathrm{S} 2$ and of unpaired durations.

\section{REFERENCES}

Allan, L. G., \& Kristofferson, A. B. Psychophysical theories of duration discrimination. Perception \& Psychophysics, 1974, 16, 26-34.

Boduroska, W. Retroactive inhibition in recent memory. Polish Psychological Bulletin, 1970, 1. 99-110.

Creelman, C. D. Human discrimination of auditory duration. Journal of the Acoustical Society of A merica, 1962, 34, 582-593.

FrANKENHAEUSER, M. Estimation of time: An experimental study. Stockholm: Almquist and Wiksell, 1959.

GreEN. D. M.. \& Swets, J. A. Signal detection theory and psychophysics. New York: Wiley, 1966.

Huppert, F., \& Singer, G. An aftereffect in judgment of auditory duration. Perception \& Psychophysics, 1967, 2, $544-546$.

Jamieson, D. G., \& Petrusic, W. M. Presentation order effects in duration discrimination. Perception \& Psychophysics, 1975, 17, 197-202. (a)

Jamieson, D. G., \& Petrusic, W. M. The dependence of timeorder error direction on stimulus range. Canadian Journal of Psychology, 1975, in press. (b)

Luce, R. D., \& Galanter, E. Discrimination. In R. D. Luce, R. R. Bush. \& E. Galanter (Eds.). Handbook of mathematical psychology (Vol. 1). New York: Wiley, 1963.

Needham, J. G. The time-error in comparison judgements. Psychological Bulletin, 1934, 31, 229-243.

PEAK. H. Time order errors in successive judgments and in reflexes. 1. Inhibition of the judgment and the reflex. Journal of Experimental Psychology, 1939, 25, 535-565.
PEAK, H. Time order errors in successive judgments and in reflexes. 1I. As a function of the first stimulus of a pair. Journal of Experimental Psychology, 1940, 26, 103-115. (a)

PEak, H. The time order errors in successive judgments and in reflexes. III. Time error theories. Dsychological Revien: 1940, 47, 1-20. (b)

Postman, L. The time-error in auditory perception. American Journal of Psychology, 1946, 59, 193-219.

Roelofs, C. O., \& Zeeman, W. P. C. The subjective duration of time. II. Acta Psychologica, 1949, 6, 289-336.

Treisman, M. Temporal discrimination and the indifference interval: Implications for a model of the "internal clock." Psychological Monographs, 1963, 77, Whole No. 576.

VRoon, P. A. The lengthening effect in sequential estimations of a short interval. Psychologische Forschung, 1972, 35, 263-276.

WICKELGREN, W. A. Unidimensional strength theory and component analysis of noise in absolute and comparative judgements. Journal of Mathematical Psychology, 1968, 5. $102-122$.

Woonrow, H. Individual differences in the reproduction of temporal intervals. American Journal of Psychology, 1933, 45. 271-281.

Woodrow, H. The effect of practice upon time order errors in the comparison of temporal intervals. Psychological Review, $1935,72,127-152$.

Woodrow, H. Time perception. In S. S. Stevens (Ed.), Handbook of experimental psychology. New York: Wiley, 1951.

WOODWORTH, R. S. Experimental psychology. New York: Holt. 1938.

Zwislocki. J. J., Ketkar, I., Cannon, N. W., \& Nodar, R. H. Loudness enhancement and summation in pairs of short sound bursts. Perception \& Psychophysics, 1974, 16, 91-95.

Zwislocki, J. J., \& Soxolich, W. G. On loudness enhancement of a tone burst by a preceding tone burst. Perception \& Psychophysics. 1974, 16, 87-90.

\section{NOTE}

1. The term "time-order error" in this paper refers only to effects observed in the comparison situation.

(Received for publication December 16, 1974; revision received April 24, 1975.) 